\title{
"BAJO EL SIGNO DE ORBE": EL PERIODISMO LITERARIO DE LINO NOVÁS CALVO DESDE ESPAÑA PARA CUBA*
}

\author{
Jesús Gómez-de-Tejada \\ IDESH. Universidad Autónoma de Chile \\ jgomezdetejada4@gmail.com
}

\begin{abstract}
RESUMEN / ABSTRACT
En agosto de 1931, Lino Novás Calvo llega a España desde Cuba como corresponsal del semanario habanero Orbe. Fiel a los propósitos editoriales que la publicación se había marcado, trata de captar el pálpito de la sociedad y la política españolas para acercar la realidad del país a los lectores cubanos. Este artículo recorre las claves de las crónicas, reportajes y entrevistas realizados por Novás Calvo para esa revista, concediendo especial importancia a su labor como entrevistador de algunas de las figuras españolas, hombres y mujeres, claves del momento. Para ello, se parte de la concepción del periodismo literario como un macrogénero periodístico caracterizado por la hibridación del periodismo y la literatura.
\end{abstract}

Palabras clave: Lino Novás Calvo, literatura cubana, escritores hispanoamericanos en España, periodismo literario, Segunda República española.

In august 1931, Lino Novás Calvo arrives to Spain from Cuba as a correspondent of Havana's magazine Orbe. True to the editorial purposes that the publication had marked, he tries to capture the hunch of society and the Spanish politics to bring the reality of the country to Cuban readers. This article covers the key of chronic journalism, reportage and interviews conducted by Novás Calvo for the magazine, granting special importance to his work as an interviewer of some of the key Spanish figures, men and women of the moment. In order to do this, the idea of literary journalism as a journalistic macro genre is conceived, which is characterized by the hybridization of journalism and literature.

KEYWORDS: Lino Novás Calvo, Cuban literature, Spanish-American writers in Spain, literary journalism, Second Spanish Republic.

Este trabajo se enmarca en el Proyecto FONDECYT Postdoctorado 2015 nº 3150177 (CONICYT, Chile), que lleva por título "La isla y sus espejos: redes de la memoria cubana del siglo XXI", del que soy investigador responsable. 
Entre 1931 y 1939, el cubano-español Lino Novás Calvo (1903-1983), tras algo más de una década en Cuba, volvió a España como corresponsal del semanario habanero Orbe, cuya existencia, bajo la dirección de Ignacio Rivero Alonso y con José Fernández de Castro como redactor jefe, se prolongó poco más de dos años (13 de marzo de 1931 - 26 de marzo de 1933). El regreso de Novás supuso un periodo de consolidación de su formación intelectual comenzada en la isla, con su participación en algunas de las principales revistas españolas, la publicación de varias de sus narraciones literarias más notorias y su plena integración en la guerra civil ${ }^{1}$. Alejada de convencionalismos y faceta fundamental de su producción artística, su labor periodística para diarios de ambos lados del Atlántico abrió una ventana a las realidades sociales, culturales, políticas y económicas tanto cubanas como españolas ${ }^{2}$.

1 La participación de Lino Novás Calvo en la vida literaria y periodística de la España republicana fue fructífera. Además de su presencia en Mundo gráfico, La Voz, El Sol o La Gaceta Literaria, destaca su colaboración en Revista de Occidente de José Ortega y Gasset, que se prolonga hasta 1936, convirtiéndolo en el escritor hispanomericano con mayor número de artículos en sus páginas (López Campillo 72). A los textos periodísticos se unieron los novelísticos y las traducciones: por un lado, El negrero. Vida novelada de Pedro Blanco Fernández de Trava (Madrid, 1933) y Un experimento en el barrio chino (Barcelona, 1936); por otro, especialmente, su traducción al español de Santuario (1933) de William Faulkner. La biografía del tratante español le supuso una cierta notoriedad en el ambiente intelectual de El Ateneo de Madrid, hasta el punto de que llegó a ser elegido Secretario de la Sección de Literatura de esta institución (Romero, Fragmentos de interior 101). A lo anterior, se añade su extensa producción cronística durante la guerra civil. Precisamente, a su llegada a Cuba en 1939, su primera colaboración periodística sería en el diario comunista Noticias de Hoy con una columna sobre la guerra civil española. Novás Calvo salió de Cuba en 1960 inconforme con la situación del país. Se instaló en Nueva York y colaboró con numerosas revistas, como por ejemplo Bohemia Libre. Entre 1967 y 1973, impartió clases de literatura hispanoamericana en la University of Syracusse. Murió en Nueva York en 1983.

Las palabras dirigidas a José María Chacón y Calvo, en una carta de 1939, ya de regreso en Cuba, describen en gran medida el proyecto periodístico y de supervivencia con que Novás Calvo había afrontado años antes su retorno a España y que mantuvo igualmente en posteriores etapas cubanas y neoyorquinas: "[i]r de Cuba a un país cualquiera [...] vivir (creo que será posible) en ese país unos cuantos meses, escribiendo y hablando de Cuba, y estudiando las cosas de allí, especialmente la vida del pueblo, el arte, las costumbres. Pasar entonces a otro país, y escribir y hablar del anterior, y así sucesivamente" (Laberinto de fuego 96). Aunque referidas al ámbito hispanoamericano y redactadas en Cuba a fines de 1939, tales afirmaciones concuerdan perfectamente con su experiencia española y parecen justamente motivadas por ella. 


\section{PERIODISMO Y LITERATURA}

En este artículo, el análisis de los textos que Novás Calvo compuso para Orbe se realiza a través de los supuestos que determinan la existencia del periodismo literario como "realidad cultural indiscutible" (López Pan y Rodríguez 230). Desde esta perspectiva, los textos analizados son descritos como hibridación del periodismo y la literatura. Su redacción basada en los modelos de la crónica, el reportaje y la entrevista, habitualmente considerados como géneros periodísticos de gran potencial respecto al uso de recursos procedentes de la literatura y de especial proclividad a encauzar el estilo personal del autor, orientan a estudiar estos trabajos dentro del periodismo literario. Sin embargo, como afirman Fernando López Pan y Beatriz Gómez Baceiredo - a partir de la terminología de Gerard Genette-, dichos géneros son constitucionalmente periodismo y solo condicionalmente literarios. Según estos autores, los textos inscritos en estas tres categorías periodísticas pueden ser literarios o no en función del reconocimiento en ellos de diversos elementos que determinen su literariedad. La recepción del lector a través de un proceso, que Genette llama de recuperación estética, es la que otorga a cada texto la pertenencia al periodismo literario. En el presente estudio, se parte de las características genéricas de la crónica, el reportaje y la entrevista, y a continuación, se determinan los elementos creativos que permiten su consideración como piezas del periodismo literario. Finalmente, se detallan los elementos temáticos más significativos de estas piezas.

Desde sus comienzos, el periodismo estableció relaciones con la literatura caracterizadas por un trasvase bidireccional y constante. A pesar de ello, el reconocimiento de la existencia de escritos simultáneamente literarios y periodísticos, productos de la fusión de ambas disciplinas, no ha sido -ni es- unánime. Las definiciones esencialistas del periodismo como información de actualidad y de la literatura como escritura de ficción sin utilidad más allá de sí misma determinan una separación nítida entre estos ámbitos (López Pan y Gómez Baceiredo).

Convencionalmente, se han establecido tres géneros periodísticos: informativo, interpretativo y de opinión. Estas compartimentaciones, inicialmente estancas, obedecen a criterios vinculados a la función social de informar, a consideraciones éticas básicas de la profesión periodística y a basamentos epistemológicos concernientes al discernimiento entre hechos y opiniones, objetividad y subjetividad, y estilo estandarizado y estilo personal (López Pan 98-99). Más adelante, nuevas teorías del conocimiento han llevado a 
considerar el periodismo en sí como "interpretación de la realidad", por lo que, en ocasiones, el trinomio se ha visto reducido a dos tipos: periodismo informativo y de opinión (Sánchez y López Pan 27).

La estricta separación entre hechos y opiniones no ha sido igual en todos los tiempos ni en todos los países. Frente al periodismo anglosajón, promotor de separar claramente entre unos y otras, el periodismo francés, el español o el hispanoamericano han sido más tendentes a mezclarlos. Tal y como afirma Susana Rotker, la aparición del New Journalism, en EE. UU. durante los años 60 del siglo XX, no significó el descubrimiento de las "relaciones promiscuas" (Chillón) entre periodismo y literatura, sino la continuación de una manifestación periodística que ya había tenido sus frutos en las crónicas de escritores hispanoamericanos como José Martí (1853-1895), Rubén Darío (1867-1916) y Joaquín Edwards Bello (1887-1968).

En España, en 1985, Sebastiá Bernal y Lluis Albert Chillón, al cuestionar la concepción de la literatura y el periodismo como actividades excluyentes, renuevan la organización de los géneros periodísticos con la introducción de una macrocategoría que denominan periodismo informativo de creación. Este macrogénero, en palabras de Bernal y Chillón, contiene textos en los que se concilia la intención informativa con la presencia de rasgos como "la subjetividad del autor, la ruptura de la compartimentación tradicional en géneros periodísticos estancos, el uso de múltiples técnicas narrativas y la renuncia a las estructuras rígidas y estereotipadas propias del periodismo convencional" (84). Por su parte, José Francisco Sánchez y López Pan comparten estas diferenciaciones (a pesar de que discutan la validez del periodismo informativo de creación como nuevo macrogénero) y la necesidad de modificar los criterios definitorios de géneros empíricos como la crónica, el reportaje y la entrevista para dar cabida a textos que añaden un carácter más creativo (Sánchez y López Pan; López Pan 102-103).

El periodismo literario, según Rafael Yanes Mesa, acoge "escritos literarios con una función informativa" ("La crónica" s.p.). Para Jorge Miguel Rodríguez Rodríguez y María Angulo Egea, se trata de un "macrogénero que, bajo otros géneros, agrupa un conjunto de textos que son al mismo tiempo Periodismo y Literatura" (Cit. en Torregrosa y Gaona 793). Singularmente, López Pan y Gómez Baceiredo señalan que el "Periodismo literario vendría a ser una de las salas de espera de la Literatura" (29; cursiva en el original). Su propuesta parte de las ideas de Genette, expuestas en "Ficción y dicción" (1991; 2003), sobre la condicionalidad literaria de ciertos escritos pragmáticos en prosa, que constitutivamente no son ni ficción narrativa ni dicción poética: "Genette 
plantea la existencia de una literatura de ficción, definida por unos contenidos fabulados, y una literatura de dicción -basada en el modo de decir-, que a su vez ampara la poesía, constitutivamente literaria, y la prosa no ficticia, que lo será de modo condicional" (López Pan 109).

En el ámbito de esta condicionalidad, López Pan y Gómez Baceiredo señalan que pertenecen al periodismo literario aquellos escritos periodísticos que, en el marco de la prensa en que han sido publicados, simultáneamente son percibidos como literatura por el lector debido al uso de recursos literarios $\mathrm{y}$, sobre todo, al logro de una intemporalidad y una pulsión humanizadora (27). Estos elementos propician un proceso de recuperación estética que se convierte en "puerta de entrada para textos pragmáticos [...] que, sin ajustarse a ninguno de los criterios constitutivos [de lo literario - narración ficticia o dicción poética-], podrían 'entrar y salir de la esfera literaria al albur de las circunstancias y según ciertas condiciones"” (López Pan 109-110).

En este estudio, se entiende el periodismo literario como un macrogénero donde se insertan textos pertenecientes a distintos géneros periodísticos, respecto a los cuales cumplen con sus características definitorias en torno a la transmisión de información, interpretación u opinión, y cuya literariedad es perceptible a partir del empleo de recursos asociados a la literatura y al estilo personalmente creativo del autor.

La crónica, el reportaje y la entrevista han sido considerados por los teóricos como los géneros periodísticos de carácter informativo e interpretativo más permeables a la incorporación de técnicas consagradas por el uso literario y más abiertos a la plasmación de la singularidad creativa del periodista. Algunos autores afirman la dificultad de delimitar tajantemente los rasgos de la crónica y el reportaje (Parratt, Géneros periodísticos), toda vez que las concepciones sobre uno y otro género dependen del momento histórico y del ámbito geográfico que se tengan en cuenta (Parrat, Introducción al reportaje 39-40). Además, la crónica como "relato interpretativo contado desde el lugar donde sucede un hecho noticioso" ha existido desde antes del periodismo (Yanes Mesa, "La crónica" s.p.). No obstante, la crítica ha especificado elementos diferenciadores. Yanes Mesa afirma que la "crónica la realiza un periodista desde el lugar de los hechos, [mientras] en el caso del reportaje su autor puede estar ausente"; añade también que, para Carlos Elías Pérez en La ciencia a través del periodismo (2003), la secuencia temporal estructura la crónica, a diferencia del carácter anexo que el eje cronológico ostenta en el reportaje (Cit. en Yanes Mesa, "La crónica" s.p.). Según Chillón, la crónica no está sujeta a "las graves responsabilidades del reportaje en lo 
que hace a la indagación y al contraste de fuentes" (377). Sánchez y López Pan delimitan una y otra al afirmar que la crónica se ocupa de una actualidad inmediata y el reportaje de una actualidad de carácter más amplio (27). Por su parte, Sonia Parratt destaca que el reportaje permanece en los límites de la interpretación, los cuales son traspasados por la crónica para adentrarse en el ámbito de la valoración (Géneros periodísticos); a la vez, ambos permanecen alejados de la opinión. Finalmente, el reportaje se entiende como un género especialmente híbrido capaz de contener todos los otros géneros, entre ellos la crónica (Yanes Mesa "El reportaje" s.p.).

Yanes Mesa afirma que, contemporáneamente, la crónica se sitúa en el límite entre la información y la opinión. Según sus palabras, la crónica es "la interpretación subjetiva de los hechos ocurridos, contados desde el lugar en el que se producen y con una implicación clara de su cronología" ("La crónica" s.p.). Asimismo, añade que "el cronista tiene la misión de informar sobre lo sucedido, de contarlo [...] desde su punto de vista. Es un relato sobre un hecho noticiable, pero en el que se incluye la valoración parcial de su autor" ("La crónica" s.p.).

Entre las características del reportaje actual, Parratt (Introducción al reportaje) señala su extensión y estructura variable; su estilo ameno; "la inclusión de antecedentes, contextualización, anécdotas y circunstancias aclarativas" a través de la incorporación de la cita literal de testimonios en forma de fragmentos dialogados o declarativos, así como la captación del ambiente por medio de la descripción de personajes, espacios y objetos; y su profundización en hechos de "actualidad prolongada y permanente" basada en múltiples fuentes (29-30). Yanes Mesa lo define como un género periodístico orientado "a profundizar en las interioridades de la noticia, en las causas y consecuencias de algún acontecimiento de actualidad, y a investigar aspectos no conocidos a partir de testimonios confidenciales o a través de la búsqueda de datos" ("El reportaje" s.p.).

Los cauces literarios que pueden reconocerse en estos géneros coinciden con aquellos que Bernal y Chillón asocian al periodismo informativo de creación. Según estos autores, dichos rasgos configuran textos que:

[no siguen] las estructuras tradicionales (la pirámide invertida, la ley del interés decreciente y sus variantes), presentan varios puntos de vista y reconstruyen escenarios, introducen el diálogo, emplean la técnica del retrato global del personaje y su entorno y utilizan un lenguaje fresco e innovador, en el que abundan las figuras retóricas y otros recursos literarios (Cit. en Sánchez y López Pan 25). 
Respecto a la entrevista como género del periodismo, Parrat explicita que su concepción no alude al simple intercambio de preguntas y respuestas por medio del cual el profesional obtiene información de la persona que es objeto de su interés. En lugar de ello, dicho género se constituye como la textualización de ese acto, es decir, "es un relato, publicado en el periódico, del diálogo sostenido entre dos o más personas, una de las cuales, asumiendo el rol de entrevistadora, es su autora" (Géneros periodísticos). Frente a la transcripción escueta de las preguntas y respuestas que caracteriza la entrevista objetiva, la entrevista literaria, también llamada de personalidad, se define por la presentación de la atmósfera en que se produce el intercambio de preguntas y respuestas; la descripción física y anímica del entrevistado; la inclusión de detalles biográficos, la estructura flexible y elíptica que altera el orden de preguntas y respuestas y que trascribe réplicas no precedidas de la cuestión correspondiente o viceversa; y la alternancia del lenguaje periodístico, fundamentalmente condensado en el diálogo entre el corresponsal y el personaje interpelado, con un estilo literario reconocible en los pasajes descriptivos y narrativos (López Hidalgo 80-87).

Según Montse Quesada, citada por Antonio López Hidalgo, a través de tales recursos, el periodista -en una relación de poder asimétrica respecto al sujeto interpelado (Arfuch; Balsebre et al.)- se transforma en creador al "mezclar la información obtenida del entrevistado con la percepción que la conversación y el ambiente hayan provocado en él” (López Hidalgo 79). De este modo, teatralización y ficcionalización se convierten en procesos clave de una escritura en que las entidades del periodista y de su interlocutor, participantes en el encuentro oral en un tiempo y espacio concretos, conviven con las del entrevistador y entrevistado, protagonistas del texto atemporal (Rueda 7, 82-84).

\section{EL PERIODISMO LITERARIO DE NOVÁS CALVO}

Las cartas de Novás Calvo a Fernández de Castro, escritas durante su estancia en España, reflejan íntimamente la esperanzada dedicación con que afrontó su puesto ante la sociedad cubana como cronista de la vida española, siempre a la búsqueda de nuevos y significativos temas, siempre alerta frente a la situación social y artística, siempre movido por el afán de originalidad y calidad -no solamente en el uso de la palabra, sino incluso en el de la imagen con que quiso ilustrar sus artículos (Novás Calvo, Laberinto de fuego 47). 
Su propósito se dirigió a satisfacer los principios editoriales con que el semanario gráfico se había definido desde sus comienzos: ofrecer información de la actualidad mundial, con especial énfasis en Cuba y España, desde una perspectiva cercana y humanizadora, con el firme compromiso de "crear un lazo de solidaridad entre Orbe y sus lectores" (Romero, "Orbe español" 13).

Los trabajos enviados a la revista cubana se dividen, por un lado, en crónicas y reportajes, y por otro, en entrevistas. Entre los primeros, pueden señalarse distinciones en función del foco temático, que permiten hablar de textos de impronta predominantemente política, social, cultural o biográfica, aunque realmente, lo político permea la totalidad de esta producción. En general, como productos de un corresponsal enviado desde Cuba para cubrir la actualidad española, las colaboraciones entregadas a Orbe se denominan como crónicas: relatos informativos, descriptivos, narrativos y explicativos de una actualidad de la que es testigo directo y que se sitúa en el espacio de España y en el tiempo de la Segunda República. Las fuentes que el propio autor identifica en su escritura, por una parte, aluden a la opinión de políticos e intelectuales (a través de la lectura de periódicos, la asistencia a mítines o conferencias, su presencia en las tertulias de café o del Ateneo, o la consulta profusa de los libros de la biblioteca de esta institución); por otra parte, el termómetro de la sociedad también lo conforma la opinión popular (por medio de lo escuchado en la calle o lo hablado en la pensión donde se aloja). A partir de ello, su prosa recrea el ambiente y construye personajes de los que reproduce su voz en estilo directo en forma de cita o diálogo:

Cuando acabó de hablar había anochecido y teníamos que salir del parque zoológico del Retiro, y la dama se dio cuenta de que había estado hablando como si soñara con un reportero y comenzó a darme con el abanico en la cabeza. "Usted lleva mi secreto ahí-dijo-; usted me ha robado. [...] usted va a poner eso que le dije en los heraldos de América. [...] ¿Cómo voy a vivir sin eso?”(España estremecida 227).

La tensión conceptual entre los niveles de valoración e interpretación asignados a la crónica desde el ámbito de la crítica está presente en la propia escritura del autor que, a menudo y como parte del rasgo metaliterario reconocible en su estilo, explicita la objetividad de su información y la posición de testigo desde la que la expresa. La estructuración cronológica del texto varía de una crónica a otra, de modo que se desplaza desde su importancia axial hasta su casi completa disolución. Eventualmente, la pérdida de su condición de testigo, el paso de una actualidad inmediata a otra más extendida y la desaparición 
del eje temporal en la organización de los hechos contados orientan a preferir la denominación de reportajes para algunos de los textos.

Novás Calvo llegó a España apenas unos meses después de las elecciones que dieron comienzo a la Segunda República ${ }^{3}$. Era un momento de eclosión de la cultura nacional, que evidenciaba una especial atención de los intelectuales hacia la política y un incremento del compromiso del gobierno con el desarrollo de la educación y las artes, lo cual permiten a Juan Pablo Fusi hablar de la politización de la intelectualidad y de la existencia de un Estado cultural (Juliá 609). Javier Gutiérrez Palacios afirma que el esplendor literario de la Edad de Plata de la cultura española se reflejó también en las páginas de los diarios, puesto que "en las tres primeras décadas del siglo XX y especialmente durante el periodo republicano", la efervescencia del momento político, más allá de "posiciones extremistas y panfletarias", contribuyó a impulsar una prensa moderna de alta calidad en la que coincidieron las plumas de "tres generaciones $-98,14$ y 27" (21, 25). Destaca, pues, en la época, un periodismo literario manifestado, sobre todo, en los géneros de la crónica y el reportaje, que enriquece - mas no inventa- la realidad, sin que de ello resulte un oscurecimiento de la misma, sino que por el contrario, precisamente a través de esa factura artística, proporciona más luz al entendimiento del lector (62-63). En cuanto a la crónica propiamente, ya en 1906, Rafael Mainar enumeraba la información, el comentario y la amenidad como sus principales características: ya que es "vida y del vivir imagen, la crónica no es, no puede ser monótona" (202-03).

Es en este contexto donde Novás Calvo pudo encontrar su sitio en la prensa española, gracias a un estilo que, según Cira Romero, es afín al New Journalism estadounidense puesto que en sus crónicas y reportajes pueden reconocerse los entrecruzamientos entre lo literario y lo factual, "el cuidado por el lenguaje, la correspondencia exacta entre lo objetivo y lo subjetivo y la adopción de puntos de vista, unido a la metaforización de la vida cotidiana" ("Orbe español" 22).

3 La proclamación de la Segunda República española, el 14 de abril de 1931, se produjo a raíz de las elecciones municipales celebradas dos días antes. El 9 de diciembre de 1931, se aprobaría la nueva Constitución y el día 15 del mismo mes, comenzaría el primero de los dos gobiernos presididos por Manuel Azaña, miembro del Partido Acción Republicana, con el apoyo fundamental del PSOE. 
Novás Calvo defendió la necesidad de un periodismo próximo a los latidos del pueblo, que conciliara la urgencia de elevar el nivel cultural de los textos con el rechazo a cualquier tipo de abstracción que limitara su accesibilidad. Entendió el periodismo como un espacio donde "cabe todo" y supo dotar a sus textos de un modo de contar popular y verosímil compatible con una alta calidad literaria e informativa (Céspedes 11-12). Su estilo ha sido descrito como "una gramática musical, de frases que se quiebran nerviosamente, emparentándose con el decir desmañado del coloquio popular, dándoles un toque supremo de verosimilitud a sus mensajes y consiguiendo así un aligeramiento conceptual que él juzgaba imprescindible" (Céspedes 11-12). En los artículos para Orbe estas ideas se materializan con nitidez en el tono conversacional y cálido que imprime a su escritura por medio de recurrentes apóstrofes al lector y el uso de un lenguaje salpicado de giros lingüísticos cubanos con que traduce elementos de la realidad española. En estos textos, más de una vez justificó su lenguaje: "La filología [...]. No llega al pueblo, que habla un lenguaje delicioso que vale más y dice más que todas las universidades" (Novás Calvo, España estremecida 177).

Entre las colaboraciones que definen su inclusión en el nuevo periodismo español de la época resalta la serie de entrevistas literarias con las que pretendió captar y transmitir para sus lectores cubanos "los puntos más sensibles" de la sociedad española (Novás Calvo, Laberinto de fuego 47). Desde que según sus palabras, llegó "a Madrid, bajo el signo de Orbe" (España estremecida 77), Novás Calvo centró gran parte de su labor como colaborador de la revista cubana en la realización de entrevistas a personajes significativos de la vida pública -intelectual, política e institucional. A menudo, vía epistolar, comentó la identidad, la conveniencia, la justificación y el resultado de las mismas con Fernández de Castro: "Para esta entrevista con Araquistáin supongo que tendrás fotografías de sobra. Enseguida pienso fajarle a Valle Inclán, D. Fernando [de los Ríos] y la Srta. [Victoria] Kent [...]. Si las entrevistas te parecen muchas para Orbe, mira de publicarlas en el Diario [de la Marina]" (Novás Calvo, Laberinto de fuego 45). La alusión a la imagen fotográfica como parte de la entrevista y, en general, de todos los artículos elaborados como corresponsal cubano en España, es parte de su esfuerzo por ofrecer a los lectores un complemento adecuado al texto, en consonancia con la política de las publicaciones gráficas ${ }^{4}$.

4 A veces, las vicisitudes que entrañaba capturar esas imágenes le provocaban una frustración que se traslucía en el texto: "Un fotógrafo ambulante se me pone a retratar todas 
Como en crónicas y reportajes, su estilo en estos trabajos mantiene un marcado carácter artístico, que los separa de la simple entrevista de información o de declaraciones y los inserta en la variante llamada de creación o literaria, cuyos pioneros, según López Hidalgo, son nombres españoles de principios del siglo XX como José López Pinillos "Pármeno", José María Carretero "El Caballero Audaz", Corpus Barga, Carmen de Burgos y Vicente A. Salaverri (97).

Novás Calvo inicia el texto con el relato del trayecto hacia el lugar de encuentro, con la justificación de la elección del sujeto entrevistado, con la presentación del espíritu latente tras los datos biográficos, con los propósitos a alcanzar como enviado de Orbe e incluso con la reflexión sobre su misma escritura periodística. Sigue la captación del ambiente -el gabinete, la sala, el camerino- a través de detalles significativos, a veces especialmente percibidos en la mínima anécdota de actores secundarios. Continúa con el instante del saludo inicial, donde hace hincapié en la actitud, en los gestos, en la indumentaria que considera funcionales para aprehender el perfil humano del personaje enfocado. Comenta el devenir de la entrevista enfatizando ocasionalmente los cambios de tono, los silencios, las miradas o los matices que acompañan a la voz al responder. Se hace presente en el intercambio de preguntas y respuestas, aludiendo a menudo al proceso mental que motiva sus cuestiones o a las circunstancias que ponen fin a la reunión. A veces, termina con la última intervención de su interlocutor; otras, se representa a sí mismo en busca de un supuesto título para el artículo, fragmento que en realidad resulta un último y sintético esfuerzo por transmitir su visión sobre el entrevistado.

\section{VISIÓN DEL PRIMER BIENIO REPUBLICANO}

Los escritos para Orbe componen un "verdadero mosaico de la vida española" (Romero, "Orbe español" 19), puesto que a través de un total de cuarenta y siete artículos dio cuenta de un amplio abanico de temas en los que con trazo personal se ocupó de personajes, asuntos e instituciones de la actualidad

estas cosas, pero alguien le ha estropeado la cámara la noche anterior y no salen. Tengo que conformarme con tomar las fotografías con mis ojos" (Novás Calvo, España estremecida 113). 
político-cultural; sin olvidar mostrar algunas pinceladas sobre la geografía de la urbe madrileña (sus rincones cotidianos, sus espacios y tiempos de ocio), o el retrato de anónimos colectivos laborales o marginados sociales, ni renunciar a ofrecer su homenaje a intelectuales cubanos asentados por entonces en el país a través de reportajes sobre autores como José María Chacón y Calvo, Fernando Ortiz, Félix Pita Rodríguez o Carlos Enríquez ${ }^{5}$.

Son numerosos los artículos en los cuales Novás Calvo siguió el decursar de la situación política entre 1931 y 1933. Su colaboración con Orbe se desarrolló entre el albor y el ocaso del primer bienio republicano. A su llegada se encontró con un gobierno provisional que recogía bajo una denominación común tendencias diversas en constante tensión. Dentro de los objetivos inmediatos de este gabinete, según Santos Juliá, estaban la promulgación de una Constitución y la designación de sus representantes definitivos; en el horizonte próximo, reformas ansiadas y a la vez polémicas: las cuestiones educativa y agraria, el enfrentamiento entre laicismo y religión, los procesos autonomistas. Entre sus primeras crónicas sobre la realidad gallega en julio de 1931 y sus postreras reflexiones sobre distintos hitos de la actualidad española -la evolución social y moral de la mujer y la expedición al Amazonas son los focos de sus últimos artículos- en mayo de 1933, se encuentra una extensa serie de textos sobre el devenir de los dos sucesivos gobiernos de Manuel Azaña. En ellos se muestra, en general, crítico, aunque paciente con el lento e inconcluso proceso reformista, y esperanzado ante una revolución popular de mayor alcance.

En un estilo frecuentemente imaginístico y popular, de tono intencionadamente cercano -no obstante las recurrentes citas literarias, filosóficas y periodísticasy argumentación casi dialógica, que informa tanto de los hechos como de las reacciones que estos suscitan, con la voz cronística siempre en primer plano, aparecen textos como "Madrid psico-político" (septiembre de 1931), "A.B.C. republicano" (octubre de 1931), "Instantáneas españolas" (mayo de 1932) o "De la España de hoy. La política de fin de año" (febrero de 1933) que se esfuerzan por informar de la marcha de la República atendiendo a su origen, sus debilidades, sus posibles logros, los obstáculos enfrentados o su incierto futuro: "Pero yo voy a trasmitirles la palabra que me dijo un estudiante

La suma de colaboraciones escritas para el semanario es de 50 textos. A los 47 escritos en España hay que sumar un cuento, "La cabeza pensante", y dos reportajes escritos en Cuba. 
hispanoamericano aquí en la Federación de Estudiantes Hispanoamericanos -y que repitió un delicioso escritor español que llega de EE.UU. mascando chicle y sentándose en los respaldos de las sillas: «Somos pueblos gastados»" (España estremecida 332). En estas crónicas, modesta y retóricamente, Novás Calvo se presenta como un espectador más de la actualidad -que cuando pregunta y no le contestan, no imagina- que da noticia de las circunstancias perceptibles, de manera que sus textos suponen "el a. b. c. de cualquier observador" (España estremecida 98).

Entre los asuntos más candentes subraya el auge del regionalismo, del que diferencia el fundamento y alcance en sus manifestaciones catalanas, vascas y gallegas; sobre este "problema palpitante de la España moderna" recoge la "voz de profeta" de Miguel de Unamuno que - en palabras de Novás Calvo- se sitúa en franca confrontación con un sentimiento que califica de aldeanismo (España estremecida 334). Repetidamente plantea la insuficiencia de la revolución de abril por su origen burgués y no obrero, a la par que la considera debida no tanto "a la fuerza impulsiva de los republicanos como al cansancio de los monárquicos", por lo que alerta ante el excesivo entusiasmo y concluye sarcásticamente afirmando que a "los republicanos les sorprendió la República" (España estremecida 99). Con mirada retrospectiva y sintética describe el año del nuevo gobierno a través de la enumeración de "once escollos" con los que había tenido que luchar desde su origen y concede como simple, pero laudable triunfo, su esforzada pervivencia (España estremecida 326). Denuncia la oposición general que sufre el gobierno desde todos los frentes y el poder transformador de la democracia que vuelve conservadores a los revolucionarios, circunstancia que, en otro artículo, personifica en Alejandro Lerroux a quien llama el "caudillo 'radical"” (España estremecida $317)^{6}$. Anota el progresivo alejamiento de los intelectuales respecto a la clase gobernante que se va evidenciando en las voces que piden un compromiso fundamentalmente estético: Antonio Marichalar, Juan Chabás, Benjamín Jarnés, Guillermo de Torre, Pedro Salinas: "llego a sospechar que esta República, formada y fundada por intelectuales, se irá quedando cada vez más sin ellos. No por ser República, sino por ser política de partidos, como

\footnotetext{
El título del artículo es "La metamorfosis de la política. Lerroux radical, caudillo y reaccionario" (marzo de 1932; publicado en abril de 1932). Alejandro Lerroux sería el encargado por Niceto Alcalá Zamora, presidente de la República, de organizar el gobierno del segundo bienio (1933-1935), para lo cual recurrió a la alianza con la Coalición Española de Derechas Autónomas (CEDA).
} 
a la postre deviene toda democracia" (España estremecida 391). La figura de Unamuno es aludida recurrentemente en diferentes artículos para significar el extremo de este distanciamiento.

Reiteradamente, Novás Calvo reivindica su condición de cronista que cuenta lo que ha visto o le han contado. La voz del reportero, como suele nombrarse a sí mismo en el texto, se califica como simple comentarista e incluso llega a proclamar la hegemonía del hecho desnudo por encima del adorno personal (España estremecida 245); sin embargo, costosamente su prosa puede calificarse de objetiva. A menudo, su discurso se detiene sin desvelar todo la verdad a la que alude el reportaje o para cortar la información e insinuar algo oculto tras la apariencia. El contenido del texto, como por ejemplo en la crónica titulada "A.B.C. republicano", hace evidente al lector la simpatía del periodista hacia la revolución obrera que, según argumenta, envuelta en la dinámica de la historia, aguarda el paso de la revolución burguesa que supuso la implantación de la Segunda República (España estremecida 107). Novás Calvo entrevista a políticos e intelectuales, acude a mítines, habla con representantes de distintos colectivos laborales y sociales, analiza las claves ideológicas de los periódicos que constituyen el conjunto de la prensa y, en definitiva, se integra en la vida de una sociedad que analiza en profundidad y con afán panorámico. El latido político es clave en sus textos como exigía la gravedad de la hora española, pero en su retrato, junto a los responsables del país, también se encuentra el hombre y la mujer anónimos sobre los que repercuten sus designios.

\section{LAS ENTREVISTAS LITERARIAS}

Son siete los personajes escogidos por Novás Calvo: Luis Araquistáin, Fernando de los Ríos, Antonio Marichalar, Carmen de Burgos, Eugenia Zuffoli, Eugenio D’Ors y Ramón del Valle-Inclán. Salvo en los casos de Araquistáin y D'Ors cuyos títulos remiten a la duración del encuentro, el resto de ellos acompaña el nombre del protagonista con la actividad o grupo social al que pertenece ${ }^{7}$.

\footnotetext{
Los títulos completos de las entrevistas publicadas en Orbe son: "Veinte minutos con Don Luis Araquistáin" (julio de 1931; publicada en septiembre de 1931); "Don Fernando de los Rios. Ministro de palabra y de justicia" (agosto de 1931; publicada en septiembre de 1931); "Los intelectuales españoles: Antonio Marichalar" (septiembre de 1931; publicada en
} 
Todos ellos, figuras destacadas de la actualidad pública, cultural y política de la Segunda República española, son transportados a Cuba por la prosa del autor, que profundiza en la personalidad de cada sujeto, según él mismo comenta, para proporcionar al lector lo que, inaprensible en la obra escrita, reside en la viveza de la palabra (España estremecida 80).

Como rasgo común, entre los motivos de selección de los personajes ofrecidos al lector cubano, además de la relevancia de sus figuras en el fondo político, social y cultural de los primeros años de la Segunda República, destaca su relación pasada -e incluso presente- con la isla caribeña. Dicho vínculo es puesto de manifiesto por el autor en la reelaboración de las palabras mantenidas durante la conversación o en la reconstrucción de sus reflexiones posteriores sobre el encuentro ${ }^{8}$. Novás Calvo profundiza en su deseo de acercar los protagonistas de los artículos a sus receptores al señalar que estos visitaron Cuba, mantienen lazos próximos con personalidades cubanas o poseen sentimientos profundos respecto al destino del país isleño.

\section{VOCES MASCULINAS}

Las conversaciones con Araquistáin, "subsecretario del Ministerio" (Novás Calvo, España estremecida 61), y Fernando de los Ríos, "señor Ministro de Justicia" (España estremecida 78), le permiten subrayar la facilidad democrática con que el ciudadano puede acceder a los líderes del gobierno, puesto que, dice Novás Calvo, "en España gobierna hoy la del talento y de la acción, y ésta no tiene cancerberos a sus entradas" (España estremecida 78.). No obstante, esa permisividad es desmentida en el caso de Manuel Azaña, sobre quien, en un artículo posterior en torno a la figura del trapero

octubre de 1931); "Las feministas. Doña Carmen de Burgos" (septiembre de 1931; publicada en noviembre de 1931) "Una actriz desde su camerino: Eugenia Zuffoli” (noviembre de 1931, publicada en enero de 1932); “3 horas con Eugenio D’Ors” (diciembre de 1931, publicada en enero de 1932); "Don Ramón del Valle-Inclán. Presidente del Ateneo" (junio de 1932, publicada en julio de 1932).

Este proceso de reelaboración del encuentro y del diálogo sostenido en él ha sido denominado de distintos modos por los teóricos. Así, por ejemplo, Roland Barthes en "Del habla a la escritura" (1981) lo designa como escripción; David Vidal, en La entrevista en radio, televisión y prensa (1998) utiliza la palabra paraoralidad (Rueda 78, 84). 
de Madrid, comenta el silencio que como respuesta recibió su petición de entrevista al Presidente del Gobierno (España estremecida 175).

En la relación de su cita con Araquistáin y Fernando de los Ríos, matiza el alcance de la influencia revolucionaria rusa en la renovación nacional iniciada en abril, ya que, según el último, "el movimiento español [...] ha sido un proceso netamente autóctono" (España estremecida 84). Igualmente, indica el papel de la cultura y los intelectuales y su situación en el momento inicial republicano, o denuncia el discreto silencio gubernamental hacia la conflictiva situación política cubana inmersa en la represión de los últimos años del machadato ${ }^{9}$. El autor profetiza sobre la relación entre España e Hispanoamérica, respecto a la cual trascribe las palabras de Fernando de los Ríos, que alude a la progresiva consolidación de su "fe en la posibilidad de un infictionado [sic] hispánico" que transformase la naturaleza de las relaciones anteriores entre los dos ámbitos (España estremecida 86) ${ }^{10}$.

El gusto de Novás Calvo por la figura de Marichalar ${ }^{11}$ le conduce a reflexionar sobre los distintos grados de "movilización" de los intelectuales españoles, que "salieron de su gabinete o de su laboratorio y se dispersaron por los ministerios o las embajadas" o se aplicaron "a la cosa pública de un modo extraoficial"; e incluso se atreve a establecer una clasificación triangular de los mismos:

Predominan entre los intelectuales españoles de hoy dos tipos; dos grupos representados, el uno por Gasset y el otro por Unamuno [...]. Unamuno es el hombre de tierra, expresión genuina del fermento más hondo y nacional de España; aquél quiere europeizar España; éste la iberiza [...]. Existe otra hornada de intelectuales proletarios -Falcón, Balbontín, Samblanca, etc.- que forma el otro cateto del triángulo.

\footnotetext{
Con este nombre se conoce al gobierno de Gerardo Machado (1871-1939), que fue presidente de la República de Cuba entre 1924 y 1933, año en que fue expulsado del poder a través de un proceso revolucionario.

10 El anfictionado es el cargo del anfictión, delegado de la anfictionía. Los anfictiones se reunían en asamblea para tratar los asuntos comunes de la confederación de las antiguas ciudades griegas. Aquí, Novás Calvo cita la opinión de Fernando de los Ríos sobre la creación de una confederación hispánica.

11 Antonio Marichalar ostentó el título nobiliario de Marqués de Montesa. La impresión del autor sobre Marichalar quedó recogida no solo en esta entrevista, sino también en su epistolario con Fernández de Castro: "Marichalar vale. No es como los monaguillos que rodean a Ortega y Gasset” (Novás Calvo, Laberinto de fuego 47).
} 
En el centro de este triángulo están los intelectuales libres, que no forman explícitamente ningún partido, pero que inevitablemente participan algo de los tres grupos. Marichalar pudiera ser el núcleo de estos (España estremecida 127).

A través de D'Ors, el autor de la entrevista centra el asunto en el aislamiento del filósofo respecto a la sociedad y el fuerte lastre de la histórica tendencia casticista española impermeable a lo universal, que le lleva a alertar ante la estrechez de los nacionalismos. En la transcripción del encuentro late un sentimiento de reserva hacia el personaje. Recelo que se percibe también en el diálogo postal con el director de Orbe, cuando Novás Calvo agradece a Fernández de Castro la publicación de la entrevista. En tono distanciado y justificativo, del que puede extraerse -sin sorpresa- una falta de afinidad con D'Ors, añade que, en general, las razones para realizarla han sido las de la nombradía del entrevistado y, en particular, unas conferencias impartidas en la Universidad de la Sorbona de París (Laberinto de fuego 49). Estos prejuicios se entienden por la religiosidad y el antisovietismo notorios de D’Ors (Pérez-Castilla), así como por su atracción — junto a autores como Rafael Sánchez Mazas o Eugenio Montes- por el fascismo (Juliá 512). No obstante, el encuentro parece atenuar la distancia y Novás Calvo deja ver un camino de comunión con su interlocutor, en el que dice descubrir un sencillo gusto por el lenguaje del pueblo. En última instancia, tras llamarlo "maestro", en un guiño habitual hacia sus lectores, termina describiendo a D’Ors como "EL CUBANO QUE NO HA ESTADO EN CUBA" (España estremecida 236; mayúsculas en el original).

Valle-Inclán, "hombre de alambre" al que define como "un cardo, como un tojo nudoso y erguido sobre el fondo eternamente verde de su región" (España estremecida 348), es presentado como uno de los "cinco Ramones" que, según se dice en el texto, "condensan las flores y las espinas de España" $(344)^{12}$. A su entrevistado lo describe por medio de una lista de adjetivos pareados: "gallego y novelista, sentimental, caballero y quimerista, arcaico y revolucionario: se llama Don Ramón María del Valle-Inclán y Montenegro”

12 A todos ellos los enumera precedidos de su región de origen, su desempeño escritural y sorprendentes e iluminadores adjetivos con que trata de aprehender la esencia de cada personaje. 
$(344)^{13}$. Novás Calvo alude a las reiteradas peticiones de entrevista que dirigió a Valle-Inclán y que finalmente le concedió con motivo de su elección como presidente de El Ateneo de Madrid, donde enfrentó la candidatura de Unamuno. El comentario, enfatizando la "gran ironía" que al referirse a una institución "cuna de republicanismo" ello llevaba implícito, argumenta que la beligerancia inconformista e incómoda de Unamuno inclinó hacia Valle-Inclán el apoyo del gobierno, que pretendía que el organismo literario quedara circunscrito a lo artístico y alejado de asuntos políticos (España estremecida 347). Sin ofrecer valoración alguna al respecto, el relato de Novás Calvo se carga de la aspereza de su interlocutor y del amargo afecto de este por la tierra gallega.

Junto a las siete entrevistas aparecidas en Orbe, pueden mencionarse otras dos publicadas en revistas diferentes. En 1932, en Revista Bimestre Cubana, Novás Calvo dio a la luz una entrevista sobre Gómez de la Serna, al que titula de "inhumano". Sobre él, acogiéndose a la autoridad de Marichalar y refutándose a sí mismo, señala que no es un humorista sino creador de un nuevo y único género: el Ramonismo, que define como el recurso de "radiografiar unas cosas con la lente de otras, abstracción hecha del punto de vista "humano"” (Novás Calvo, "Ramón el inhumano" 52).

Recién llegado a España, Novás Calvo había entrevistado también a Giménez Caballero. Firmada el 23 de agosto de 1931 y aparecida el 15 de septiembre de ese año en La Gaceta Literaria, fue la primera de estas entrevistas en salir en prensa, aunque en julio ya había entrevistado a Araquistáin. Titulada "El Robinsón literario llega a Cuba", contiene una semblanza asombrada del director de La Gaceta donde deja repetida constancia de su esfuerzo editorial y su contundente rechazo del gobierno republicano y de los literatos, que "han dejado de ser escritores [...] pero no han llegado a ser políticos" (Novás Calvo, "El Robinsón literario" 2) $)^{14}$.

13 Los otros cuatro son Pérez de Ayala, Menéndez Pidal, Ramón y Cajal y Gómez de la Serna. Más adelante, añadirá los nombres de Juan Ramón Jiménez y Ramón María Tenreiro, diputado gallego.

14 La aparición de los textos de Novás Calvo en La Gaceta se produce una vez que ya se ha hecho evidente el giro fascista de Giménez Caballero y que muchos intelectuales le han dado la espalda a la que, desde 1927, había servido como expresión unitaria del arte de vanguardia y que, hacia 1930, se había ido escindiendo en diversas tendencias políticas hasta que, el 15 de agosto de 1931, su director se convirtió en el único redactor del periódico. De este modo, varios números aparecieron bajo el subtítulo de El Robinsón literario de España (o la República de las letras) debidos exclusivamente a la firma de Giménez Caballero (Molina 113). Una carta de Novás Calvo recoge su personal visión sobre el polémico personaje, mirada 


\section{VOCES DE MUJER}

$\mathrm{Al}$ abordar las entrevistas realizadas a dos conocidas figuras femeninas del momento, especialmente a la periodista y novelista Carmen de Burgos, resalta el interés que Novás Calvo despliega respecto a la situación de la mujer en España, hacia su rol socio-laboral y el alcance del feminismo español. Si no puede decirse que la mujer ocupe un lugar predominante en sus textos periodísticos, sí es posible al menos citar la recurrencia del asunto. A los escritos para Orbe se unen los que, centrados en la participación femenina en la guerra civil, publicó para los periódicos del frente republicano - Ayuda, Mundo Obrero y Frente Rojo. Sobre la situación de la mujer en la década de los años 30, especialmente, llama la atención el artículo aparecido en el rotativo madrileño La Voz en el verano de 1934, "La mujer en las sociedades modernas", que supone una contrastiva reflexión entre las diversas circunstancias de esta en los pueblos árabes y chinos, en los EE.UU. y la URSS, y en la misma Cuba, aunque nada dice de la situación en la República española, público al que se dirige. Novás Calvo constata con júbilo la llegada de la mujer al lado del hombre en aquellas sociedades donde ello supone la igualdad en el trabajo y en la familia, como ocurre en las sociedades soviéticas y cubanas, en cuyo seno, en su opinión, el hogar se había visto fortalecido por la incorporación de la mujer a la vida pública; todo lo contrario del caso estadounidense.

El resabio conservador, que el lector actual puede encontrar en el artículo, se hace obvio en otro posterior de idéntico tema y estructura escrito para el periódico cubano Información -en el que mantuvo una columna de opinión durante 1945 y principios de 1946. En esta ocasión, el título es "Hogar y vida pública" y vuelve a focalizar las curvas del proceso de emancipación femenina a ambos lados del Atlántico. A pesar de que parte de él aparece como un elogio a la mujer cubana, justificado en la capacidad de esta para combinar las labores de casa con las de su empleo, el texto no escapa a la consabida perspectiva patriarcal -se omite cualquier alusión a la responsabilidad compartida por el hombre. La doble jornada de la mujer queda bendecida desde una visión

enriquecida en el contraste con los intelectuales de Revista de Occidente: "Como sabes, fui a ver a Giménez Caballero. Le hice la entrevista [...]. Este personaje, que sé no te simpatiza, y que a mí tampoco me simpatiza -por gesticulante y porque en el fondo tiene un matiz de fascista- es sin embargo un hombre de ingenio y de cultura" (Novás Calvo, Laberinto de fuego 47-48). 
de época que, en el devenir histórico del proceso de la lucha por la igualdad de género, aún se ve marcada por roles tradicionalmente subordinantes de la mujer ${ }^{15}$. Más vindicativas se ofrecen sus palabras para los lectores cubanos de Orbe en "Por la aldea de Galicia" -creadoras de malestar entre sus paisanos (Romero, "Orbe español" 15)- a través de las que describe la sobrecarga de la mujer gallega en la jornada familiar: "La mujer trabaja tanto, a veces más que el hombre. Va con él al campo y rivaliza con él en resistencia. [...] amasa y cuece el pan; cose la ropa; cocina, acarrea el agua de la fuente; cría los hijos... El hombre no toca las labores domésticas (Novás Calvo, España estremecida 49).

En ese sentido, el reconocimiento del papel fundamental de la República, no solo en la incorporación de la mujer al ámbito público, sino también al universitario y al político, se encuentra recogido en el reportaje "La Residencia de Señoritas" (1932), donde a los logros de la institución Novás Calvo opone el inconveniente de la poca capacidad de sus instalaciones, alguna alusión estereotipada a la femeneidad del ambiente y, apenas entre líneas, la indicación de su limitado alcance a una circunscripción burguesa. La inquietud por reflejar el devenir de la mujer española en el proceso republicano continúa en los artículos "Las modistillas" y "La señorita española en 1933. De la misa a las misses". Si su descripción de la residencia femenina señalaba el ambiente de las clases medias, en estos dos, Novás Calvo se detiene en el tipo más popular de la mujer trabajadora mediante la conocida figura de la "modistilla" (ampliamente recogida en la literatura de la época), de la que avisa no hará un retrato realista sino mitológico. A través del mismo, se ofrece una imagen que, en un estilo inconexo, secretea al lector la singularidad de estas jóvenes -lenguaje, vestimenta, actitudes, rutinas, condiciones laborales- e incluso, emprende la defensa de un casticismo ya desaparecido, a su juicio, en la burguesa española. El dibujo de este grupo genérico y socio-laboral, basado en su experiencia y en los relatos que le cuentan los hombres que "siempre andan a la caza de ellas" (España estremecida 311), no deja de estar desprovisto de la picardía con que se las caracterizó oral y literariamente ${ }^{16}$.

\footnotetext{
15 "It must be noted that the patriarchal structure has the special characteristic of being the most important factor of social inequality even as it is the most imperceptible. In addition, it serves to reinforce gender roles and the subordinate position of women" (Díaz Vallina 1).

16 En "Las modistillas de Madrid, tradición y realidad (1884-1920)", Núñez Orgaz afirma que "el popular término modistillas, con que se las denominaba en Madrid, está reflejando la escasa consideración social de que gozaban. Este término despectivo, iba unido
} 
La ambigüedad de Novás Calvo, en estos acercamientos a la situación femenina, se desarrolla en un estilo característicamente elíptico, con grandes dosis de anfibología y esguinces de tono humorístico entre los que inserta aseveraciones arquetípicamente masculinas sobre la mujer, que chocan con su propia expresión de ideas progresistas, defensoras de la igualdad de género. En sus artículos, deja mezclarse la aceptación inequívoca de los nuevos roles de la mujer y la admiración de sus logros con términos exterioristas y animalizadores -"gatitas", "jíbaras" (España estremecida 312, 394)-, así como con expresiones alusivas a conductas de la mujer relacionadas con el orden o la limpieza atravesadas de cierto determinismo biologicista: "la mujer española lleva el hogar, el hogar que lleva dentro y que no siempre ve en materia, a donde quiera que va" (España estremecida 279); "el mover las cosas con hilillos invisibles será siempre femenino" (España estremecida 283). La conciencia proletaria y subversora de Novás Calvo incluye y demanda la integración de la mujer en los espacios públicos -sociales y laborales-, pero en algunos pasajes, ocasionalmente, parece limitada por un patriarcalismo epocal que supura bajo la expresión de ciertas distinciones entre el hombre y la mujer ${ }^{17}$. Estas representaciones, desde la teoría crítica feminista, son susceptibles de ser leídas como proyecciones culturales de la ideología masculina dominante por las que el signo mujer adquiere un esencialismo naturalista que lo adhiere a perfiles concretos diseñados de antemano (Richard 734).

A las dos entrevistas mantenidas con Carmen de Burgos y Eugenia Zuffoli, habría que sumar la realizada a Victoria Kent; sin embargo, Romero devela en la introducción a su recopilación de los artículos de Novás Calvo que, hasta la fecha, dicho texto no ha podido ser localizado (Romero, "Orbe español” 12) ${ }^{18}$.

a la imagen de jóvenes bulliciosas, frecuentadoras de bailes y verbenas, de moralidad dudosa, aficionadas, algunas a la bebida; muchas, a la lectura 'dañina'; y, la mayor parte, a la búsqueda de marido" (Cit. en Díaz Sánchez 281).

17 En el artículo "La Residencia de Señoritas", al describir las instalaciones de la institución diferencia repetida y arquetípicamente el mundo masculino y el femenino: "No hay nada que ordenar. No hay donde echarse como sobre tierra, ni donde tirar el abrigo, ni se puede uno descalzar, $[\ldots]$ ni puede hacer ninguna de esas cosas salvajes que nos gusta hacer a los hombres. Las mujeres tienen aquí su pequeña república, como en un mundo de cristal" (España estremecida 278).

18 Victoria Kent fue un nombre importante en el devenir de la incorporación de la mujer a la sociedad pública española. En 1931 fue elegida Directora General de Prisiones y diputada del Partido Republicano Radical Socialista. 
Sorprendentemente, la actitud con que Novás Calvo recoge la presencia femenina en la vida pública, la intensidad y los logros de este colectivo, condensados en el renombre de Carmen de Burgos, se ve relativizada sensiblemente por el tono y el contenido del comentario epistolar dirigido a Fernández de Castro: "Las feministas son aquí una filfa. Sin embargo yo dije otra cosa. ¿Qué iba a decir puesto que fui a hacerle una entrevista a su presidenta?" (Novás Calvo, Laberinto de fuego 48). Puede suponerse que el comentario de Novás Calvo, que entrevista a Carmen de Burgos en septiembre de 1931, sobre la falacia del movimiento, parta del hecho de que las reivindicaciones de las asociaciones feministas aún estaban lejos de alcanzar el grado de las sostenidas por sus iguales en otras latitudes, incluyendo Cuba, donde la mujer gozaba del derecho al divorcio y a la patria potestad desde finales de los años diez; si bien para el derecho al voto debieron esperar hasta 1934, frente a las españolas que lo obtuvieron en diciembre de 1931 (González 274). El negativo juicio manifestado epistolarmente por el autor sobre el feminismo español pudo deberse también al paradójico enfrentamiento entre los feminismos laicista y católico; o dentro de la tendencia laica, a la disputa, no menos contradictoria, entre aquellas que, como Clara Campoamor, habían defendido el derecho al sufragio femenino, y aquellas otras que, como Kent, habían preconizado su posposición a la espera de que una apropiada formación de la mujer en sus derechos de igualdad y libertad no la hiciera fácil presa de la influencia de la Iglesia en detrimento del futuro de la República (Moreno). Tal suposición se refuerza al leer como el autor incluye "la beatería femenina" como uno de los pilares de las tendencias reaccionarias (España estremecida 320).

Al comienzo del relato del encuentro con Carmen de Burgos justifica el artículo por su deseo de personificar la labor feminista en España a través de un nombre concreto, "porque siempre será edificante y fortalecedor ver cómo la propia obra activa de una mujer da el primer mentís a los que se oponen a la reinvidicación de sus derechos" (España estremecida 135). Estas palabras sitúan a Novás Calvo con claridad entre los defensores de la presencia pública femenina; sin embargo, la preocupación por la disolución del núcleo familiar, que manifestó posteriormente en los artículos comentados arriba, aparece tempranamente en una de las preguntas dirigidas a su interlocutora: "-Pero y el hogar... ¿desaparecerá el hogar tradicional?” (España estremecida 142). En el encendido elogio de las conquistas de Carmen de Burgos con que abre el texto, pese a todo, se percibe una clara conciencia de la estereotipia sexista presente en algunos usos del lenguaje, lo que matiza la posible carga negativa entrevista en otros pasajes: "Su perseverancia y tesón [los de Carmen de Burgos] 
son verdaderamente masculinos, en el sentido que tenemos tradicionalmente para hablar" (España estremecida 137).

El texto sobre la actriz de origen italiano Eugenia Zuffoli está marcado por el tono reflexivo en torno a las máscaras de la artista y la práctica periodística. En él teoriza sobre el amplio margen de invención permitido en la entrevista literaria, que lejos de recoger las palabras exactas del interlocutor, reconstruye el intercambio verbal a posteriori en función "de lo que resulte del diálogo que surge siempre entre el que escribe y su propia imaginación" (España estremecida 211). Novás Calvo refleja en su narración y en la reproducción creativa de preguntas y respuestas una palpable tensión en un encuentro del que ambos individuos parecen esperar poco. Fracasa el entrevistador en su objetivo de dibujar para sus lectores la mujer que hay detrás de la actriz y fracasa la entrevistada en su afán por presentar como real la careta tras la que se esconde. No pierde la ocasión de indagar sobre la militancia feminista de la Zuffoli y, a continuación, tras ironizar sutilmente sobre la tibieza que percibe en su contestación, responde con sorna y vuelve a patentizar la literaturización ficcionalizante del encuentro como valor de este género periodístico: "-No, no -le digo-; usted debe simpatizar ortodoxamente con la revolución; aunque usted diga lo contrario yo afirmaré eso. La admirarán todavía más" (España estremecida 214).

\section{CONCLUSIÓN}

Los itinerarios trasatlánticos de Novás Calvo le llevaron en pasajes con retorno de España a Cuba, de Cuba a España y de nuevo a la isla caribeña. En España, entre 1931 y 1939, su singular prosa halló acomodo en novelas y relatos de ficción, numerosas traducciones y una cantidad ingente de artículos, reportajes, crónicas y entrevistas de carácter profundamente artístico, a través de los cuales, y en los dos sentidos transoceánicos, reflejó su percepción -su vivencia- de ambos espacios.

Sus trabajos para Orbe fusionan la información de la actualidad española y la creatividad del autor en un texto que se ajusta plenamente a los rasgos del periodismo literario. Como observador -"un hombre con una cámara, un periódico y un traje regularcito", tal y como se autorretrata en una de sus crónicas (España estremecida 184)-, su mirada atenta y su escritura testimonial lo convirtieron en un comentarista privilegiado que supo pulsar la política, radiografiar la sociedad y calibrar el espíritu de un país convulso. Como 
entrevistador, dirigió su inquietud hacia protagonistas de distintos ámbitos de la realidad cultural y política nacional. En sus entrevistas, al predominio de escritores más o menos comprometidos con el gobierno republicano, se suma la presencia de voces femeninas que remarcan el interés que Novás Calvo sintió por detallar la situación de la mujer en la sociedad naciente. Ocho entrevistas desde España para Cuba -sin contar las realizadas a Kent y Giménez Caballero- que se añaden por méritos propios al periodismo literario de alta calidad del autor y a la actividad fecunda de su segunda etapa española, que se cerró con el término de la guerra civil y su regreso a La Habana a fines de 1939.

\section{BIBLIOGRAFÍA}

Arfuch, Leonor. La interioridad pública: la entrevista como género. Buenos Aires: Instituto de Investigaciones de la Facultad de Ciencias Sociales, 1992.

Balsebre, Armand, Manuel Mateu y David Vidal. La entrevista en radio, televisión y prensa. Madrid: Cátedra, 1998.

Bernal, Sebastiá y Lluís Albert Chillón. Periodismo informativo de creación. Barcelona: Mitre, 1985.

Céspedes Díaz, Norge. "Machacando en su máquina de escribir". Introducción. Lino Novás Calvo. Lino Novás Calvo: periodista encontrado. Ed. Norge Céspedes Díaz. Matanzas, Cuba: Aldabón. 2004. 7-28.

Chillón, Lluís Albert. Periodismo y Literatura: una tradición de relaciones promiscuas. Bellaterra: Universitat Autònoma de Barcelona, Servei de Publicacions, 1999.

Díaz Sánchez, Pilar. "Del taller de costura a la fábrica. El trabajo de las mujeres en la confección-textil madrileña”. Cuadernos de Historia Contemporánea 21 (1999): 279-293.

Díaz Vallina, Elvira. "The Invisibility and the Visibility of Women in the History of Cuba". Cuban Women. History, Contradictions and Contemporary Challenges. Eds. Colleen Lundy, y Norma Vasallo Barrueta. Ottawa: Carleton University Graphic Services, 2001. 1-21.

Genette, Gerard. Ficción y Dicción. Barcelona: Lumen, 1991.

Gónzalez, Julio César. "Historia de la mujer en Cuba: del feminismo liberal a la acción política femenina". Diez nuevas miradas de historia de Cuba. Ed. José Antonio Piqueras Arenas. Castelló de la Plana: Publicacions de la Universitat de Jaume I, D. L, 1998. 271-285.

Gutiérrez Palacios, Javier. República, periodismo y literatura. La cuestión politica en el periodismo literario durante la Segunda República española. Madrid: Tecnos, 2005.

Juliá, Santos, et al. La España del siglo XX. Madrid: Marcial Pons Historia, 2007.

López Campillo, Evelyne. La Revista de Occidente y la formación de minorías (1923-1936).

Madrid: Taurus, 1972. 
López Hidalgo, Antonio. Las entrevistas periodísticas de José María Carretero. Córdoba: Diputación de Córdoba, 1999.

López Pan, Fernando. "Periodismo literario: entre la literatura constitutiva y la condicional". Ámbitos 19 (2010): 97-116.

y Beatriz Gómez Baceiredo. "El periodismo literario como sala de espera de la literatura". Periodismo literario. Naturaleza, antecedentes, paradigmas y perspectivas. Eds. Jorge Miguel Rodríguez Rodríguez, y María Angulo Egea. Madrid: Fragua, 2010. 21-40.

y Jorge Rodríguez. "Periodismo literario. Una aproximación desde la Periodística". Retórica, Literatura y Periodismo. Actas del V Seminario Emilio Castelar. Eds. José Antonio Hernández Guerrero et al. Cádiz: UCA, 2006. 223-236.

Mainar, Rafael. El arte del periodista. 1906. Pról. Juan Luis Cebrián. Barcelona: Ediciones Destino, 2005.

Molina, César Antonio. Medio siglo de prensa literaria española (1900-1950). Madrid: Endymion, 1990.

Moreno Seco, Mónica. "República, género y religión. Las mujeres ante la política laicista republicana”. Mujer y política en la España contemporánea (1868-1936). Eds. María Concepción Marcos del Olmo y Rafael Serrano García. Valladolid: Universidad de Valladolid, 2012. 183-202.

Novás Calvo, Lino. España estremecida (Crónicas en la revista Orbe). Introd., comp. y notas Cira Romero. Sevilla: Renacimiento, 2013.

Laberinto de fuego. Epistolario de Lino Novás Calvo. Ed. y pról. Cira Romero. La Habana: Ediciones La Memoria; Centro Cultural Pablo de la Torriente Brau, 2008. "Hogar y vida pública". Información, 4 marzo 1945: 4.

"La mujer en las sociedades modernas". La Voz, 16 julio 1934: 4.

"Ramón el inhumano. Mi incursión a Pombo". Revista Bimestre Cubana 1 (julioagosto 1932): 52-58.

“El Robinsón literario llega a Cuba". La Gaceta Literaria, 15 septiembre 1931: 1-2.

Parratt, Sonia F. Géneros periodísticos en prensa. Quito: Ciespal, 2008.

Introducción al reportaje: antecedentes, actualidad y perspectivas. Santiago de Compostela: Universidade, Servicio de Publicacións e Intercambio Cientifico, 2003.

Pérez-Castilla Álvarez, Javier. "El Pensamiento político de Eugenio d Ors”. Tesis Doctoral. Universidade da Coruña, 1998. http://www.tdx.cat/handle/10803/15264?show=full

Richard, Nelly. "Feminismo, experiencia y representación". Revista Iberoamericana 176-177 (1996): 733-744.

Romero, Cira. “Orbe español de Lino Novás Calvo". Introducción. Lino Novás Calvo. España estremecida (Crónicas en la revista Orbe). Introd., comp. y notas. Cira Romero. Sevilla: Renacimiento, 2013. 9-24.

Fragmentos de interior. Lino Novás Calvo: su voz entre otras voces. Santiago de Cuba: Oriente, 2010.

Rotker, Susana. La invención de la crónica. México, D.F.: Fondo de Cultura Económica, 2005. 
Rueda Acedo, Alicia Rita. Miradas transatlánticas: el periodismo literario de Elena Poniatowska y Rosa Montero. West Lafayette, Indiana: Purdue UP, 2012.

Sánchez, José Francisco y Fernando López Pan. "Tipologías de géneros periodísticos en España. Hacia un nuevo paradigma". Comunicación y Estudios Universitarios 8 (1998): 15-35.

Torregrosa Carmona, Juan-Francisco y Carmen Gaona Pisonero. “Antecedentes y perspectivas sobre periodismo literario español durante el siglo XX”. Historia y Comunicación Social 18 (2013): 789-798.

Yanes Mesa, Rafael. "La crónica, un género del periodismo literario equidistante". Espéculo: Revista de Estudios Literarios 32 (2006).

https://pendientedemigracion.ucm.es/info/especulo/numero32/cronica.html

"El reportaje, texto informativo aglutinador de distintos géneros periodísticos". Espéculo: Revista de Estudios Literarios 34 (2006-2007). https://pendientedemigracion. ucm.es/info/especulo/numero34/reportaj.html 